\title{
Close-range vertical photography for measuring cover changes in perennial grasslands
}

\author{
LAUREN T. BENNETT, TERRY S. JUDD, AND MARK A. ADAMS
}

Authors are research associate, Department of Botany, University of Western Australia, Nedlands, Western Australia 6907, Australia, Instructional Designer, Biomedical Multimedia Unit, Faculty of Medicine, Dentistry and Health Sciences, University of Melbourne, Parkville, Victoria 3056, Australia, and associate professor, Department of Botany, University of Western Australia, Nedlands, Western Australia 6907, Australia. At the time of the research, the sec ond author was Associate Lecturer, Agriculture Faculty, University of Western Australia.

\begin{abstract}
We describe a method of close-range vertical photography and digital image analysis for measuring changes in total projective cover in perennial tussock grasslands of semi-arid Australia. Repeated photographs of permanent plots $\left(1 \mathrm{~m}^{2}\right)$ were classified using supervised image analysis, providing a clear and objective record of the effects of single-burns on grass cover relative to controls. Computer simulations of the photographic set-up indicated that errors due to camera perspective were consistently less than $4 \%$ across a range of cover classes. Other errors, including misclassification error, were not quantified because simplified laboratory tasks indicated that conventional field methods, such as point sampling and visual estimation, provided unreliable estimates of grass cover and were therefore not suitable benchmarks for assessing the photographic method. However, the presented data indicate that the photographic method was sufficiently accurate and precise to measure treatment effects over time and to elucidate relationships between independent growth parameters across a range of cover conditions. In addition, the photographic method was inexpensive, involved minimal field time, and utilised commercial software to classify images. It has the clear advantage over more traditional methods of providing outputs that are readily archived for retrospective studies.
\end{abstract}

Key Words: bunch grass, northwest Australia, permanent quadrats, prescribed burning, rangelands, Themeda triandra Forsskal

Traditionally, the methods employed in rangeland programs for monitoring changes in herbaceous cover have included visual assessment, point sampling, or transects. However, the fine-texture of grasses and the frequently large areas to be assessed lead to errors in estimation that are either large, unknown or observerspecific (Walker 1970, Sykes et al. 1983). These problems are confounded in arid environments where the patchy nature of the vegetation produces infrequent recordings and, as a result, wide confidence intervals (Friedel and Shaw 1987). Large or unknown errors have the potential to mask early signs of change and are

Research was funded by a Collaborative Research Grant from the Australian Research Council with Hamersley Iron Pty Ltd as the industrial partner. Authors wish to thank staff from Hamersley Iron Development Group and Hamersley Station for logistical support and members of the Ecosystems Research Group, University of Western Australia, for help in the field.

Manuscript accepted 17 Feb. 2000.

\section{Resumen}

Describimos un método de fotografáa vertical de rango estrecho y de an-lisis de imagen digital para medir los cambios en la cobertura total proyectiva de pastizales perennes amacollados de la región semiáida de Australia. Fotografáas repetidas de parcelas permanentes $\left(1 \mathrm{~m}^{2}\right)$ se clasificaron utilizando el an·lisis de imagen supervisada, proveyendo un registro claro y objetivo de los efectos de la quema simple en la cobertura de los zacates en relación a las parcelas control. Simulaciones computarizadas de las fotografáas indicaron que los errores debidos a la perspectiva de la camara fueron consistentemente menores al $4 \%$ a través del rango de clases de cobertura. Otros errores, incluyendo el error de clasificación equivoca, no se cuantificaron porque las técnica simplificadas de laboratorio indicaron que los métodos convencionales de campo, tales como el muestreo de puntos y la estimación visual, proporcionaron estimaciones poco confiables de la cobertura de los zacates, y por lo tanto, no fueron una referencia confiable para evaluar el método fotogr-fico. Sin embargo, los datos que se presentan indican que el método fotogr'fico fue suficientemente certero $y$ preciso para medir los efectos de los tratamientos a través del tiempo y elucidar relaciones entre los par'metros independientes de crecimiento a lo largo de un rango de condiciones de cobertura. Adem·s, el método fotogr·fico fue barato, requirió un tiempo mánimo en el campo y utilizo programas computacionales comerciales para clasificar las im.genes. Este método tiene la clara ventaja sobre los métodos tradicionales de proveer salidas f-cilmente archivables para utilizarlas en estudios retrospectivos.

even more problematic where field data is scaled up, for example, in calibrations of remotely sensed data. Equally, variable errors are undesirable in experimental situations where accuracy and precision are required to differentiate natural variation from treatment effects (Kennedy and Addison 1987, Buttler 1992, Stampfli 1992).

Previous authors have discussed the potential of close-range vertical photography (Cooper 1924, Owens et al. 1985) and digital imaging (Roshier et al. 1997) to measure changes in vegetation cover over small areas. However, these techniques were either equipment-intensive (Roshier et al. 1997) and time-consuming (Owens et al. 1985) or were too early to take advantage of automated and objective image analysis (Cooper 1924). None were supported by systematically collected data. 
Our objective was to demonstrate the use of close-range vertical photography and computerised image analysis in measuring changes in total cover of perennial tussock grasslands in semi-arid Australia. Using images of treatment plots over 2 years, we examined the potential of this method for providing objective measures of grass cover over a range of growth conditions. Relationships were described between cover across successive dates in permanent treatment plots and between cover and total biomass in temporary plots. Errors due to camera perspective were estimated using computer models of the photographic set-up. Finally, to evaluate the potential of more traditional methods for providing estimates of 'true' grass cover against which the photographic method could be assessed, we quantified errors in point sampling and visual estimation using highly simplified laboratory tasks.

\section{Materials and Methods}

\section{Study sites}

Two study sites, $11 \mathrm{~km}$ apart, were located on Hamersley Station ( $22^{\circ} 17^{\prime} \mathrm{S}$ $\left.117^{\circ} 40^{\prime} \mathrm{E}\right)$ in the remote Pilbara region, northwest Australia (about 1,700 km north of the laboratory in Perth). The station occupies 224,000 ha, has been a pastoral lease since 1878 , and currently runs 5,000 to 6,000 cattle. The climate is sub-tropical and semi-arid. Annual rainfall is $356 \pm$ $153 \mathrm{~mm}$ (81-year mean \pm SD) falling on an average of 28 days mainly after summer cyclones (December to February). Air temperatures range from warm in winter (mean minimum and maximum of 11 and $24^{\circ} \mathrm{C}$ in July) to hot in summer (mean minimum and maximum of 26 and $40^{\circ} \mathrm{C}$ in January). Mean soil temperatures at $5 \mathrm{~cm}$ depth typically exceed $30^{\circ} \mathrm{C}$ from October to March with mean maxima greater than $40^{\circ} \mathrm{C}$ for the same months as measured from 1996 to 1998 at 1 site. Both sites were flat with soils derived from Quaternary alluvium. Soils were vertisols characterised by red swelling clays underlain by calcrete at about $60 \mathrm{~cm}$ depth.

Sites were located within perennial tussock grasslands dominated by a single species, kangaroo grass (Themeda trian dra Forsskal), with ephemeral forbs less than $3 \%$ by weight (L.T. Bennett and M. A. Adams, unpublished data). Basal cover, of about $15 \%$, was uniformly distributed across each site with litter concentrated around tussocks and with predominantly bare soil between tussocks. Both sites were more than $2.5 \mathrm{~km}$ from the nearest water source and were of good range condition with no obvious erosion features associated with degradation (Tongway and Hindley 1995). Perennial tussock grasses, or 'bunch' grasses, are widely distributed throughout tropical, sub-tropical, and temperate Australia in a range of vegetation types. Kangaroo grass is a warm season perennial, characterised by tall flowering stems (up to $2 \mathrm{~m}$ ), that occurs in all Australian states and in parts of South Africa and eastern Asia (Moore 1970). Kangaroo grass is often managed by regular burning in temperate and tropical zones but the use of prescribed fire in semi-arid regions such as the Pilbara has not been fully evaluated.

\section{Treatment and plot design}

A single experimental area of 1 ha was fenced at each site to exclude grazing. Treatment plots of $5 \times 5 \mathrm{~m}$ were randomised in 4 complete blocks and were separated by $5 \mathrm{~m}$ buffer zones. 'Burn' and control plots were randomly distributed amongst 5 other treatments involving single and combined additions of $\mathrm{N}$ and $\mathrm{P}(50 \mathrm{~kg}$ $\mathrm{ha}^{-1} \mathrm{~N}, 25 \mathrm{~kg} \mathrm{ha}^{-1} \mathrm{P}$ ) and additions of water either alone or with a combined NP addition. To examine interactions between block and treatment (Underwood 1997), we included an additional random replicate of both control and 'burn' treatments in each block, increasing the total number of treatment plots at each site to 36 ( $(2$ treatments $\mathrm{x} 4$ blocks $\mathrm{x} 2$ replicates $)+(5$ treatments $\mathrm{x}$ 4 blocks)). Since our primary aim was to demonstrate and evaluate the photographic method rather than to interpret treatment effects, we have included all data from control and 'burn' plots because it was the most complete data set. Examination of effects of nutrient and water additions was beyond the scope of this paper and only limited data from these treatments were included to illustrate relationships between biomass and cover (see below).

'Burn' plots in the same block were ignited in sequence over 2 consecutive evenings in late November 1996 (1 evening per site). During burning, wind speeds were negligible, air temperatures ranged from 31 to $38^{\circ} \mathrm{C}$ and relative humidity was 9 to $15 \%$. Plots were ignited on all sides and fire consumed all aboveground biomass within 2 to $4 \mathrm{~min}$, leaving a minimal cover of ash around tussock bases. Flame heights, monitored using video recording, were consistently less than $1 \mathrm{~m}$ and there was no increase in soil temperatures at $2 \mathrm{~cm}$ depth for the duration of the burns.

The first rain of a wet summer (494 $\mathrm{mm}$ ) fell about 20 days after burning and, by March 1997, most of the burnt tussocks had successfully recovered. An extended dry period followed (130 mm from March 1997 to February 1998 inclusive), before an average autumn (115 $\mathrm{mm}$ from March to May 1998) and an above-average winter (202 mm from mid-June to August) in 1998 (data from 2 stations within 2 to 32 $\mathrm{km}$ of sites).

\section{Photography and image analysis}

A single permanent sub-plot of $1 \times 1 \mathrm{~m}$ was established at the center of each treatment plot. These sub-plots were marked by 2 steel 'locating rods' in diagonally opposite corners which allowed a portable $1 \mathrm{~m}^{2}$ quadrat, mounted on legs, to be accurately placed at each sampling date (Fig. 1).

The permanent sub-plots were photographed using close-range vertical photography on 5 October 1996 (before treatment), 2 December 1996 (burnt only), 21 March 1997 (after good summer rains), 29 June 1997, 12 November 1997, 6 June 1998 (after an extended dry period), and 1 October 1998 (after good winter rains). At each date (except June 1998), an equivalent 'biomass' sub-plot $\left(1 \mathrm{~m}^{2}\right)$ was photographed in the surrounding treated area prior to complete harvest. All permanent sub-plots were photographed at each date but the number of 'biomass' sub-plots ranged from 2 to 4 per treatment per site according to logistical constraints of each sampling trip. Biomass was not sampled in June 1998 because heavy rains prevented further access to sites. Samples were separated in the field into litter, ephemeral forbs and standing kangaroo grass. After drying $\left(75^{\circ} \mathrm{C}\right.$ for 48 hours) and weighing, a sub-sample of the standing kangaroo grass (about $30 \%$ by mass) was further sorted into green foliage, standing dead foliage, persistent 'crowns' at tussock bases, flowering stems and seed heads. Limited data from 'biomass' sub-plots were included here to examine relationships between total projective cover and total aboveground biomass, and to aid interpretation of cover changes in permanent sub-plots using, for example, proportional changes in biomass components. Detailed analysis of treatment effects on biomass components will not be presented here.

Photographs were taken with a $35 \mathrm{~mm}$ SLR camera (Canon EOS 100, Canon Inc., Tokyo, Japan) fitted with a $35 \mathrm{~mm}$ lens. The camera was mounted, at $2 \mathrm{~m}$ height, on a portable, self-supporting aluminium stand (Fig. 1) equipped with a collapsible camera arm and 2 telescopic legs for ease of transport. Bubble levels were used to 


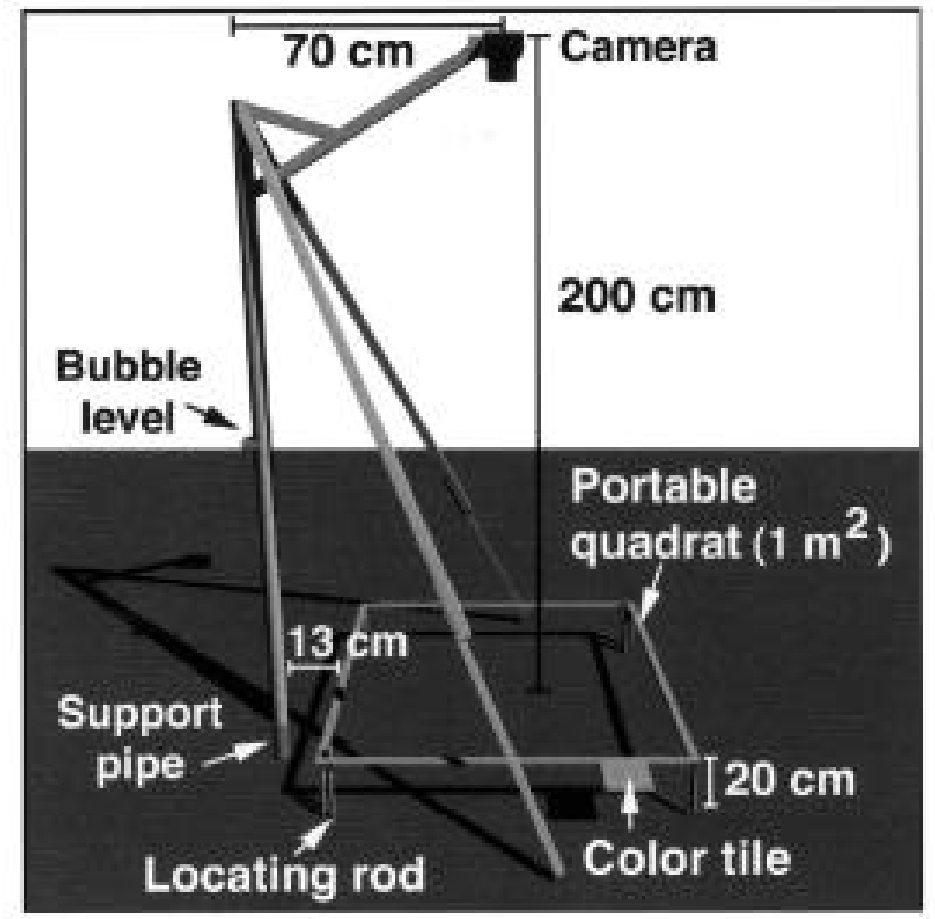

Fig. 1. Schematic diagram of the photographic set-up. The camera was mounted using a quick-release mechanism and its vertical position was checked by placing a hand-held bubble level against the camera lens (not shown). The support pipe and 2 locating rods (in diagonally opposite corners) were permanently placed to mark the location of permanent sub-plots. The camera stand was attached to a base-plate when photographing temporary 'biomass' sub-plots.

ensure that the stand, camera, and resulting images were vertical. Using standard slide film (negative dimensions 24 x 36 $\mathrm{mm}$ ) and a camera focal length of $35 \mathrm{~mm}$, the imaged area, of about $1.4 \times 2.1 \mathrm{~m}$, adequately covered a $1 \mathrm{~m}^{2}$ sub-plot. A lesser focal length (for example, $28 \mathrm{~mm}$ ) would increase the angle of coverage but would increase lens distortion, whereas a greater focal length (for example, $50 \mathrm{~mm}$ ) would decrease distortion but would require a less practical camera height of about $3 \mathrm{~m}$ to cover the same ground area. To ensure uniform lighting, the sub-plot and surrounding area was shaded with a screen of close-mesh cloth and a flash was used. A tile with a number of colored squares ('color tile', Fig. 1) was attached to the side of the portable quadrat to assist with color correction of images during later editing. Images were captured on 100 ASA color slide film (Sensia II 100, Fuji Photo Film Co., Ltd., Tokyo, Japan). One person could easily manage the camera stand and 2 persons could comfortably photograph a whole site of 36 permanent sub-plots within 2 to 2.5 hours.

The central 24 x $30 \mathrm{~mm}$ of each slide, which included the outer-edges of the quadrat and the color tile, was scanned using a high resolution film scanner
('Nikon LS-1000', Nikon Inc., Melville, N.Y., optical resolution $2,400 \mathrm{dpi}$ ), to create a $600 \times 750$ pixel image at $72 \mathrm{dpi}$. These raw images were saved as uncompressed JPEG files and were edited and analysed using Adobe Photoshop (Adobe Systems Inc., San Jose, Calif.). Individual images were subsequently adjusted for color by using the black, white, and grey points on the color tile, and by increasing both contrast and brightness by $50 \%$. The area defined by the internal edges of the quadrat $\left(1 \mathrm{~m}^{2}\right)$ was copied and rescaled to give a final image size of $500 \times 500$ pixels. Thus, each pixel represented a ground area of about $2 \times 2 \mathrm{~mm}$.

Images were analysed for cover in batches according to site and date to accommodate changes in soil brightness and lighting conditions. Total projective plant cover, including standing kangaroo grass and the minor components of litter and ephemeral forbs, was estimated by selecting and deleting soil-colored pixels as follows:

1. Two control and 2 'burn' images, representing the full range of cover for that site and date, were combined in one image (that is, $1,000 \times 1,000$ pixels).
2. The combined image was converted from 24-bit ( $2^{24}$ or millions of colors) to 8 -bit ( $2^{8}$ or 256 colors) to create a custom 'Color Look Up Table' (CLUT) that was weighted towards the spectrum of the image.

3. All images were converted to 8-bit color using the custom CLUT created in step 2 .

4. Soil colors (in this case browns and reds) were selected from the CLUT to create a customised color range.

5. Pixels within this color range were selected and recolored white, the remaining pixels (that is, plant cover) were recolored black (Fig. 2) and the percentage of black pixels was recorded.

Using Photoshop's automated 'action' and 'batch' commands (version 4 or later), 36 cropped images could be analysed for total cover in less than $90 \mathrm{~min}$. This time included visual checks for accuracy by comparing classified images with raw images.

\section{Errors in photographic method}

Since cover was estimated using images taken from a single camera point, we expected some errors due to displacement associated with tussock height and to lens distortion. We estimated these errors across a range of covers using computergenerated 3-D models. We compared vertically-projected 'model' cover with cover estimated from the perspective of a virtual 'camera'. Virtual 'tussocks' were constructed using a 3-D animation package (Specular Infini-D, Specular International Ltd., Amherst, Mass.) and were designed according to field-observations of leaf length (maximum $30 \mathrm{~cm}$ ) and leaf angle (most $<45^{\circ}$ from the horizontal). Each virtual 'tussock' consisted of 28 identical flat, linear 'leaves' joined at the base and arranged evenly around the central axis at a range of angles ( 6 'leaves' at each of 15 , 30,45 , and $60^{\circ}$ and 4 leaves at $75^{\circ}$ from the horizontal). We created a range of 'tussock' sizes by varying the length of constituent 'leaves' between 10 and 30 $\mathrm{cm}$. Varying numbers of 'tussocks' were randomly arranged within a scaled $2 \times 2 \mathrm{~m}$ area, within which a $1 \times 1 \mathrm{~m}$ 'quadrat' was centrally located at a height of $20 \mathrm{~cm}$. A virtual 'camera', configured to simulate a $35 \mathrm{~mm}$ SLR camera with a $35 \mathrm{~mm}$ lens, was positioned at $2 \mathrm{~m}$ height directly above the central $1 \mathrm{~m}^{2}$ 'quadrat'. That is, the set-up of the virtual 'camera' was a geometrically accurate model of the field set-up (Fig. 1) and the distortion and displacement modeled by the virtual 'camera' was equivalent to that associated with the real camera in the field. 


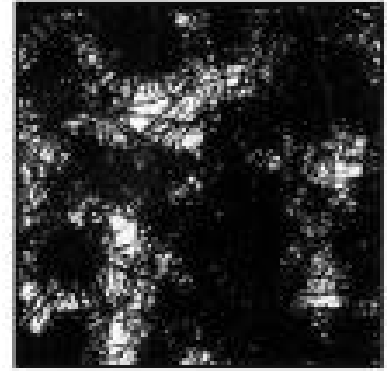

Oct. 1996: $80 \%$

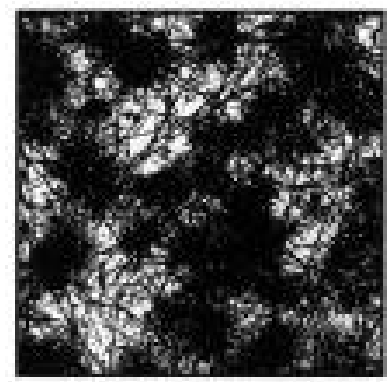

Nov. 1997: $70 \%$

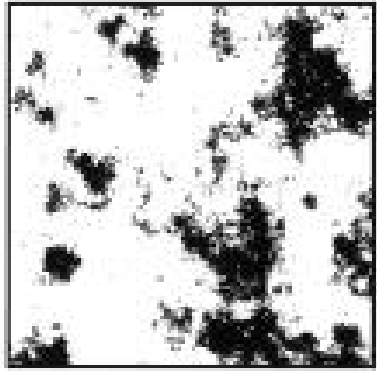

Nov. 1996: $20 \%$

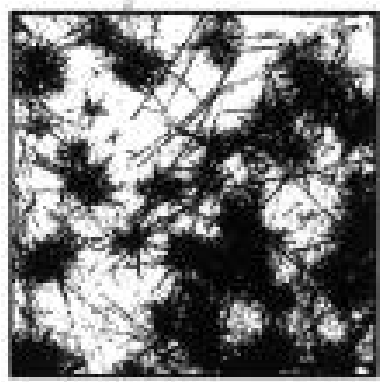

Jun. $1998: 48 \%$

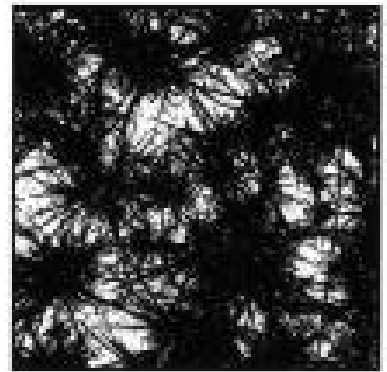

Mar. 1997: 73\%

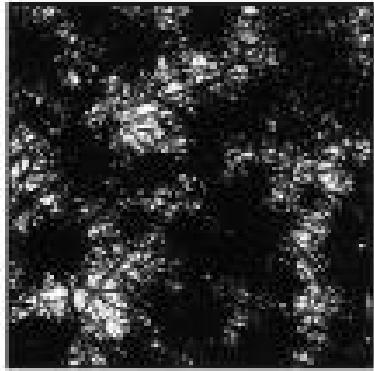

Jun. 1997: $80 \%$

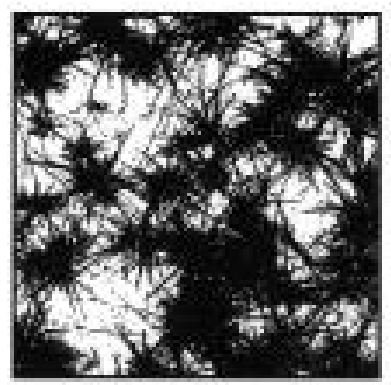

Oct. $1998: 57 \%$

Fig. 2. Sequence of classified images of the same permanent 'burn' sub-plot showing seasonal changes in total projective cover (that is, standing kangaroo grass and the minor components of litter and ephemeral forbs). Burns were conducted in November 1996.

Two 'images' of the modeled $2 \times 2 \mathrm{~m}$ area were generated-the first was a direct vertical projection at $20 \mathrm{~cm}$ height (used for 'model' cover), and the second a 'camera' view (for 'estimated model' cover). Each 'image' was cropped to the internal edges of the central 'quadrat' before measurement of total cover using color discrimination of 'tussock' and background pixels. To reflect frequency distributions of cover in the field, this procedure was repeated 5 times in each of 5 cover classes (20 to $40 \%, 40$ to $60 \%, 60$ to $70 \%, 70$ to $80 \%$, and 80 to $90 \%$ ) giving a range of 'model' covers from 25 to $88 \%$. The lower limit was near that measured in the field and the upper limit was restricted by the number of tussocks that could physically fit within the $2 \times 2 \mathrm{~m}$ area. Thus, while not an exact representation of field conditions because, for example, the distribution of litter around tussock bases was not simulated, the model allowed examination of potential error across a range of cover conditions. We did not examine errors due to topographic displacement, since both sites in this study were flat; however, we envisage that the camera attachment could be adapted to allow rotation so that the camera was positioned parallel with the main slope while the stand was kept on a vertical plane.
Additional errors in the photographic method included the misclassification of pixels. We considered these errors to be minimal as soil and plant colors were easily distinguished and classified images were carefully checked for accuracy against raw images. Quantifying total error, including misclassification error, would require a measure of 'true' cover against which the photographic method could be assessed. Preliminary evaluations at the study sites indicated that traditional field estimates of cover, such as point sampling and visual estimation, were prone to errors associated with observer subjectivity and inconsistency and could not provide reliable cover estimates. Further analysis of point sampling and visual estimation, using greatly simplified tasks in the laboratory (see below), confirmed that these methods were unreliable and could not be used to 'truth' our estimates of grass cover. Instead, we used indirect indicators to illustrate the photographic method's accuracy and precision, such as the strength of relationships between biomass and photographic cover in 'biomass' sub-plots, and between photographic cover on successive sampling dates in permanent sub-plots (given that the cover estimates from each date were independently derived using date-specific color tables).

\section{Errors in other methods of cover esti- mation}

As mentioned above, we assessed the potential errors in 2 traditional field measures of cover-point sampling and visual estimation-using simplified tasks in the laboratory. This involved estimating the 'cover' of black pixels in classified blackand-white images of permanent $1 \mathrm{~m}^{2}$ subplots (Fig. 2). Classified images were used because they contained the same fine-textured patterning as quadrats in the field, and because, unlike raw images, the actual 'cover' was known, allowing an exact calculation of the accuracy of each estimate ('percentage black' minus 'estimated percentage black'). As such, the measured errors were conservative because the use of 2-dimensional, duo-tone images would decrease errors due to, for example, observer fatigue and observer perspective in the field.

Five classified images ('replicates') from each of 6 cover classes (20 to $40 \%$, 40 to $60 \%, 60$ to $70 \%, 70$ to $80 \%, 80$ to $90 \%$, and 90 to $100 \%$ ) were chosen to reflect frequency distributions of cover in the field, giving a range of 'percentage black' from 22 to $97 \%$. To assess pointsampling, sets of random 'points' were generated using a purpose-built computer program. Each 'point' was a single pixel (out of a total 250,000 pixels per image) 


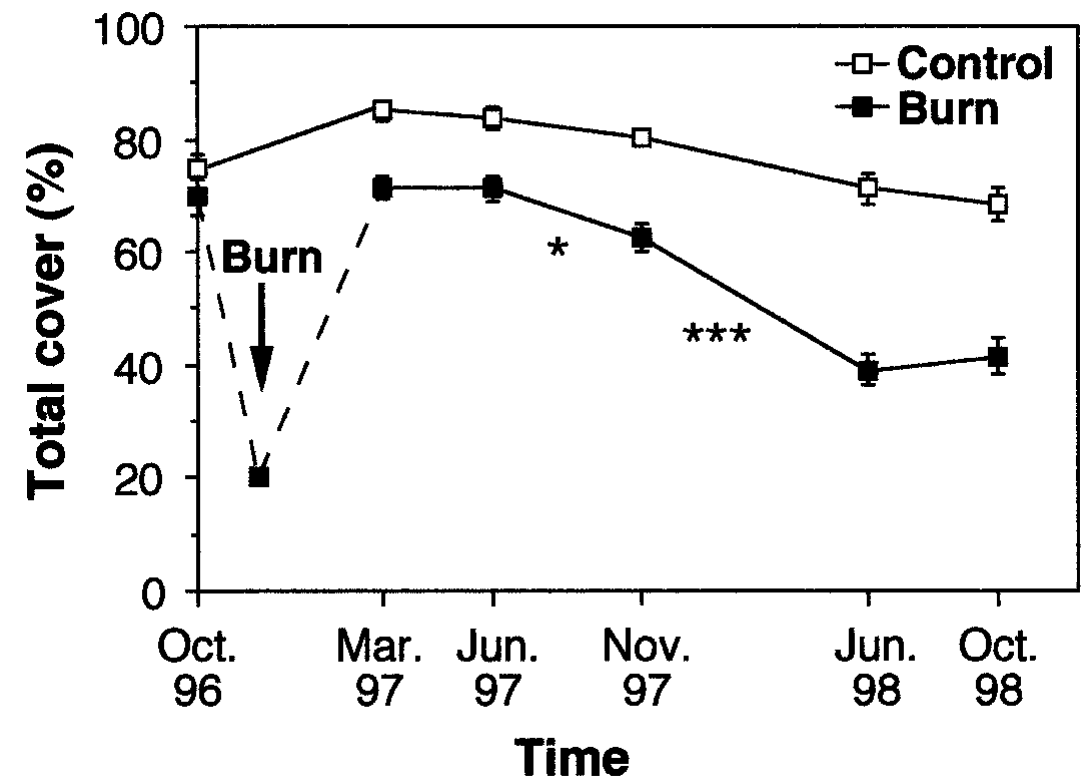

Fig. 3. Changes in total projective cover (including standing kangaroo grass and minor components of litter and forbs) in permanent sub-plots of control and 'burn' treatments. Values are means across site and block $(n=16$; bars $=$ SEM). Asterisks indicate significant differences between treatments in the change in cover between 2 successive dates $(*, * * *$ significant at $P \leq 0.05$ and 0.001 , respectively).

equivalent to a ground area of $2 \times 2 \mathrm{~mm}$. For each of the 30 test images, 5 sets of each of $10,20,50,100,200,500$, and 1,000 points were sampled (a total of 35 sets per image). The points in each set were classified as either black or white and the 'estimated percentage black' calculated. For visual estimation of cover, the same 30 test images were printed for observation by 5 trained ecologists with similar practical experience of herbaceous cover estimation. Images were sampled at random for inclusion in 2 'arrangements' each comprised of 6 images on 5 pages. Before estimating the 'cover' of black pixels for each arrangement, each observer studied 6 black-and-white images illustrating the full range of covers. These reference images were then removed and covers of test images were estimated, to the nearest $1 \%$, at the observer's leisure (typically 20 seconds per image).

\section{Statistical analyses}

Effects of treatment (control vs 'burn'), site, and block on changes in photographic cover of permanent sub-plots between 2 successive sampling dates were tested using the difference in cover as the dependent variable in an analysis of variance with block nested within site. Since permanent sub-plots were repeatedly photographed, the additional effect of sampling date was tested using cover as the biomass in 'biomass' sub-plots, and between cover in permanent sub-plots dependent variable in a multivariate repeated measures analysis of variance (after Rowell and Walters 1976, Green 1993). Relationships between cover and across successive dates, were examined using scatter plots. Differences between regression lines were tested using co-variate analysis.

Effects of cover class on simulated photographic error were tested using the difference between 'model' and 'estimated model' cover in a single factor analysis of variance. For point sampling of classified images, effects of cover class, replicate, and number of points on absolute differences between 'percentage black' and 'estimated percentage black', were analysed using a partially nested analysis of variance with replicate nested within cover class. A similar model was used to examine effects of cover class, replicate, observer, and image arrangement on visual estimates of 'percentage black' in classified images. All analyses used the models of SuperANOVA (Abacus Concepts, Inc., Berkeley, Calif.).

\section{Results and Discussion}

Treatment and seasonal effects measured using photographic method

Images of the permanent sub-plots provided a clear record of seasonal changes in growth form and cover of the perennial grasses. Most images showed excellent discrimination between soil and plant material and cover estimates were easily

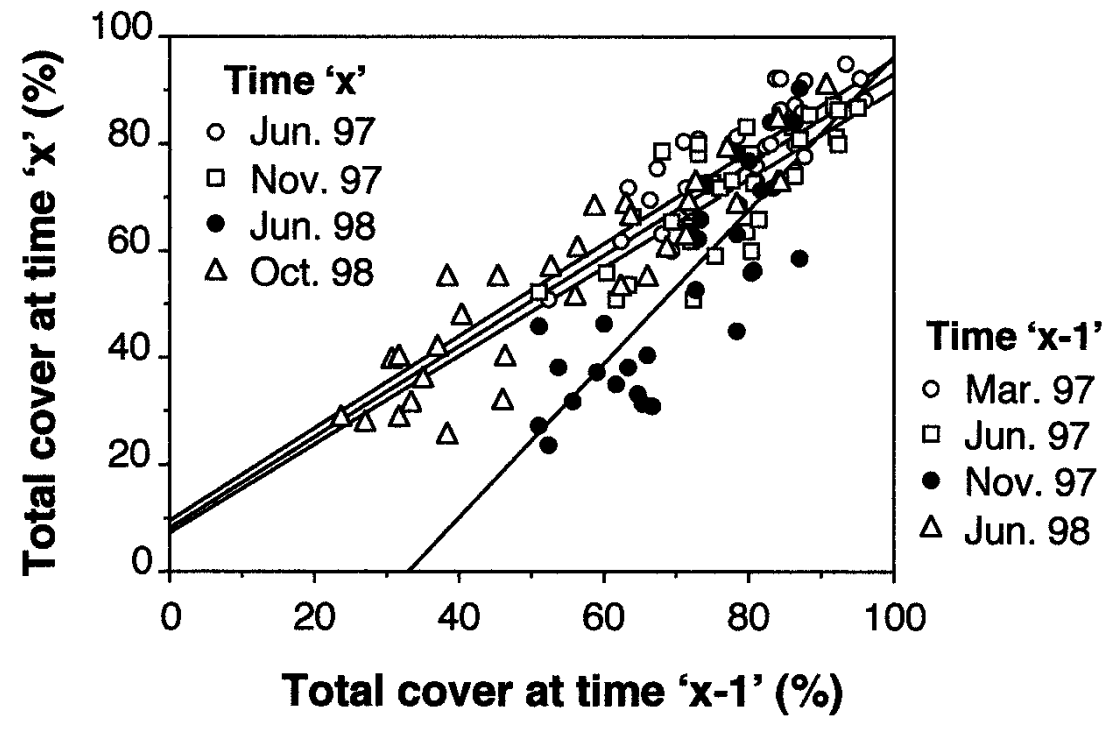

Fig. 4. Relationships between total projective cover in permanent sub-plots at any sampling date (time ' $x$ ') and total cover at the previous sampling date (time ' $x-1$ '). The slope and intercept of the regression line between covers in June 1998 and November 1997 (black circles) were significantly different $(P<0.001)$ from other regressions $(Y=-47.2+1.4 \mathrm{X}$; adjusted $r^{2}=0.71$ ). Regression lines where time ' $x$ ' represented June 1997, November 1997 and October 1998 were not significantly different (combined regression: $\mathrm{Y}=\mathbf{8 . 0}+0.9 \mathrm{X}$; adjusted $\mathbf{r}^{2}=0.81$ ). The relationship between cover in March 1997 and October 1996 was removed for clarity because data were clustered in the top right corner. 
obtained using the described image-analysis technique. A sequence of classified images from a 'burn' plot (Fig. 2) clearly illustrated both the recovery of tussocks after fire and the periods of growth and decline. Tussocks were compact with relatively upright foliage (maximum length 30 $\mathrm{cm}$ ) during periods of active growth (March 1997 and October 1998). As the time since rain increased (June 1997 to June 1998), tussocks were reduced to low, rounded hummocks (leaf length $\leq 15 \mathrm{~cm}$ ). Litter was consistently concentrated around tussock bases, leaving open spaces between tussocks at all dates, and averaged $10 \%$ of aboveground biomass for the study period (data from control 'biomass' sub-plots). Ephemeral forbs were never more than $3 \%$ of aboveground biomass and typically contributed less than $1 \%$ of total plant projective cover. Tall flowering stems, produced after the summer rains of 1996/97, were flattened by strong winds and added to projective cover while they persisted (June 1997 and November 1997). Movement of these stems sometimes affected image clarity; the problem was only significant in 'N-added' subplots where stem biomass and height were significantly increased after summer rains (L. T. Bennett and M. A. Adams, unpublished data).

The utility of an objective and consistent method for estimating total projective cover was demonstrated by clear treatment effects through time (Fig. 3) and strong relationships between cover on successive dates (Fig. 4). Using multivariate repeated measures analysis of variance, we detected significant effects of both treatment $(\mathrm{P}<$ $0.001)$ and sampling date $(\mathrm{P}<0.001)$ on total cover in permanent sub-plots (effects of site and block were insignificant in all analyses). Burning reduced total projective cover at all sampling dates (Fig. 3). Moreover, a significant interaction between treatment and date indicated that cover in 'burn' and control sub-plots responded differently to seasonal changes. For example, decreases in cover between June 1997 and November 1997 and between November 1997 and June 1998 were significantly greater in 'burn' subplots relative to control sub-plots using the difference in cover between 2 dates as the dependent variable in an univariate analysis of variance. It seems likely that removal of cover by burning increased the exposure of plants during the hot and abnormally dry summer of 1997/98 (December 1997 to February 1998). Retained cover in control sub-plots provided direct 'insulation' or otherwise ame-

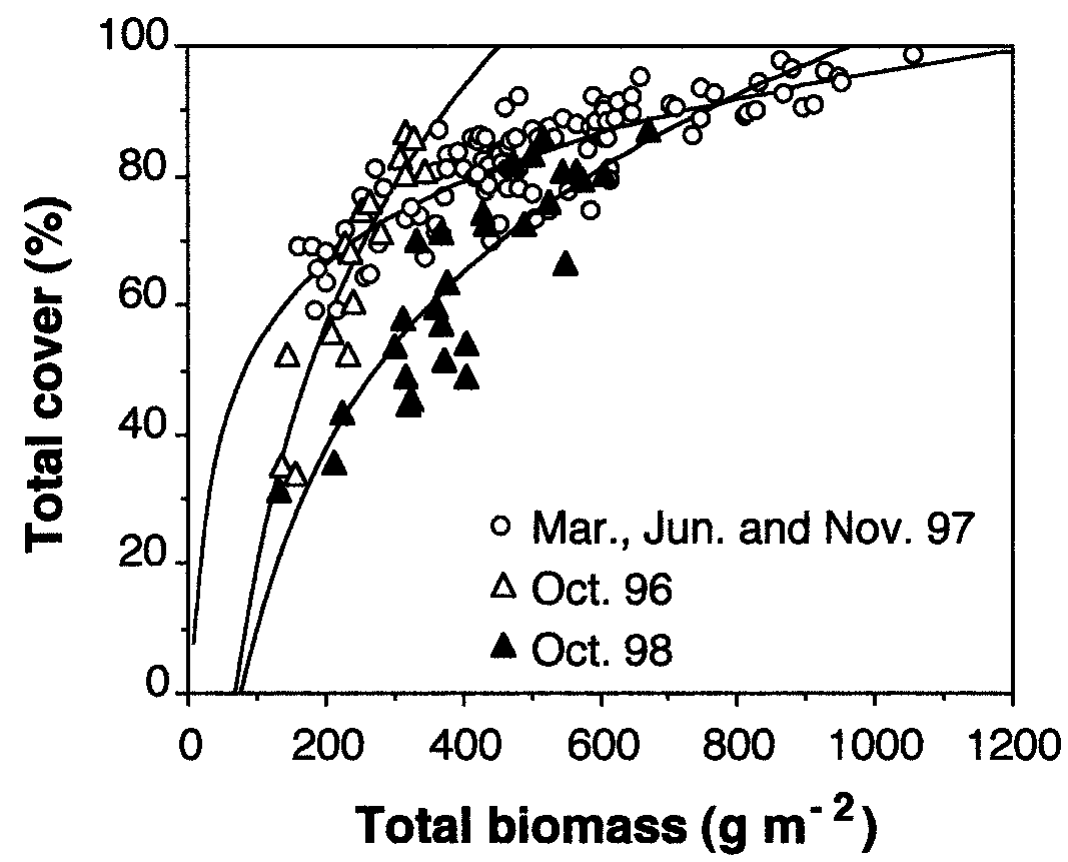

Fig. 5. Relationships between total projective cover and total aboveground biomass (that is, standing kangaroo grass, litter and ephemeral forbs) in 'biomass' sub-plots. In order to increase the range covered, data were from control and 'burn' treatments and from treatments involving additions of nutrients and water. Lines of best fit were logarithmic (shown) and were not significantly different for the 3 dates in $1997(Y=-30+42 \operatorname{logX}$; adjusted $\left.r^{2}=0.72\right)$. Relationships were different for October $1996(Y=-224+122 \operatorname{logX}$; adjusted $\left.r^{2}=0.83\right)$ and October $1998\left(Y=-172+91 \log X ; \operatorname{adjusted} r^{2}=0.74\right)$.

liorated local microclimate, and helped to prolong leaf function and residence time in an extremely arid environment. This interpretation was supported by relationships between cover near the start of summer in November 1997 and at the next sampling date in June 1998 (Fig. 4). The slope of the regression for these 2 dates was significantly greater than for other consecutive dates. A simple and clear explanation is that where cover before the onset of the hot dry summer was less than $70 \%$ (as it was in most 'burn' sub-plots), subsequent changes in cover were greater than in periods of less severe weather. Since data from 'burn' sub-plots were included to demonstrate the potential of the photographic method in monitoring treatment effects through time (Austin 1981), a detailed interpretation of treatment effects is not included here and is the subject of ongoing research.

Strong relationships between projective cover and total aboveground biomass (Fig. 5 ) indicated the accuracy of cover estimates from image analysis and demonstrated the method's practical application. The strength of these relationships was probably due to the predominance of a single grass species and the relative absence of spreading forbs. However, as in other studies of perennial grasslands (Friedel and Shaw 1987), there was no universal relationship between cover and biomass. Instead, relationships varied according to the time of sampling, with different equations for October 1996, March to November 1997, and October 1998 (Fig. 5 ). These equations represented growth in different seasons within different years, following rains in autumn 1996, summer 1996/97 and winter 1998, indicating that relationships between cover and biomass were 'fixed' between periods of growth and that the form of the relationship was determined by the season of rain and the magnitude of growth responses. For example, less cover was required to produce up to $400 \mathrm{~g} \mathrm{~m}^{-2}$ of biomass in October 1998 , after good winter rains, than in other months (Fig. 5). The different form of the relationship in October 1998 was probably due to a combination of the greater proportional mass of green foliage relative to all other dates $(17 \%$ vs $12 \%$, data from 'biomass' sub-plots) and the more upright orientation of foliage (see Fig. 2). These characteristics were, in turn, due to the season of growth - to the favourable conditions for new growth associated with 'effective' winter rainfall and to the above-mentioned effects of the preceding dry period on other components of the standing biomass. These data indicate that 
Table 1. Absolute difference (\%) between actual and estimated cover for each of 3 cover methods. Actual cover was 'model' cover for the virtual 'camera', and 'percentage black' for point sampling and visual estimation. Values are across all observations of individual actual covers and by actual cover classes.

\begin{tabular}{|c|c|c|c|c|c|c|c|c|c|c|}
\hline \multirow[b]{2}{*}{ Method } & \multirow[b]{2}{*}{$\mathrm{n}$} & \multicolumn{3}{|c|}{ All observations } & \multicolumn{6}{|c|}{ Cover class $(\%)$} \\
\hline & & $\mathrm{x}$ & SD & Range & $\begin{array}{l}20- \\
40\end{array}$ & $\begin{array}{l}40- \\
60\end{array}$ & $\begin{array}{l}60- \\
70\end{array}$ & $\begin{array}{l}70- \\
80\end{array}$ & $\begin{array}{l}80- \\
90\end{array}$ & $\begin{array}{c}90- \\
100\end{array}$ \\
\hline & & $(\%)$ & & $(\%)$ & -- & 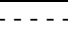 & -- & & $-\cdots$ & $-\cdots$ \\
\hline 10 points & 150 & 10 & 7.4 & $0-33$ & 11 & 12 & 11 & 12 & 10 & 6 \\
\hline 20 points & 150 & 8 & 6.5 & $0-31$ & 7 & 10 & 9 & 7 & 7 & 5 \\
\hline 50 points* & 150 & 4 & 3.3 & $0-20$ & 4 & 4 & 6 & 5 & 3 & 3 \\
\hline 500 points** & 150 & 2 & 1.1 & $0-6$ & 2 & 2 & 2 & 1 & 1 & 1 \\
\hline 1,000 points** & 150 & 1 & 0.9 & $0-5$ & 2 & 2 & 1 & 1 & 1 & 1 \\
\hline Visual estimation $^{2}$ & & & & & & & & & & \\
\hline All observers $(\mathrm{n}=5) * * *$ & 300 & 7 & 6.4 & $0-30$ & 6 & 10 & 9 & 6 & 4 & 4 \\
\hline Most accurate observer & 60 & 4 & 3.6 & $0-13$ & 4 & 5 & 7 & 3 & 3 & 2 \\
\hline Least accurate observer** & 60 & 14 & 8.3 & $0-30$ & 11 & 20 & 18 & 16 & 10 & 7 \\
\hline
\end{tabular}

All 'estimated model' covers were less than 'model' covers (by $4 \%$ on average). 'Model' cover ranged from 25 to $88 \%$ and was the vertically projected cover of computer models of grass 'tussocks' in a $1 \mathrm{~m}^{2}$ quadrat. 'Estimated model' cover was measured using a virtual 'camera' ( $35 \mathrm{~mm}$ lens) at $2 \mathrm{~m}$ above the center of each simulated quadrat.

'Percentage black' ranged from 22 to $97 \%$ and was the percentage of black pixels in classified images of $1 \mathrm{~m}^{2}$ treatment sub-plots. 'Estimated percentage black' was measured by computerised point sampling or by visual estimation using the same classified black-and-white images.

$*, * *, * * *$ Significant effect of cover class at $\mathrm{P} \leq 0.05,0.01$, and 0.001 , respectively.

substantial errors may result from assuming consistent relationships between total cover and total biomass. Estimates of productivity from cover at large scales should therefore take into account measures of grass form (for example, foliage orientation) and of the proportional mass of green material (analogous to measures of greenness in satellite imagery, Pickup et al. 1994).

\section{Errors in estimates of cover and} advantages of photographic method

Using computer models of grass 'tussocks' and a virtual 'camera', we found a linear relationship, with a slope near unity, between 'estimated model' cover (using a 'camera' view) and 'model' cover (direct vertical projection at $20 \mathrm{~cm}$ height). The relationship between these measures was strong ('estimated model' $=-2.09+(0.97$ 'model'); adjusted $\mathrm{r}^{2}=1.00$ ), as might be expected, and clearly demonstrated that 'estimated model' cover was always less than 'model' cover, with differences averaging 4\% (range from 1 to $7 \%$ ) irrespective of cover class (Table 1). These data show that perspective errors associated with the photographic method were constant and that they could be accounted for through systematic adjustment. Alternatively, cover estimates from the photographic method would not need to be adjusted for perspective in many experimental situations where relative rather than absolute differences between, for example, treatments or sampling dates, were of interest.

In contrast to the consistency of perspective errors in the photographic method, errors using point sampling or visual estimation of classified images were significantly different between cover classes (Table 1). On average, absolute differences between 'percentage black' and 'estimated percentage black', using either of these methods, were greatest where 'percentage black' was 40 to $60 \%$ or 60 to $70 \%$ and least where 'percentage black' was 90 to $100 \%$ (Table 1). This is consistent with field studies by Sykes et al. (1983) that errors in visual estimates of ground cover were greatest near covers of $50 \%$ and least at the extremes of 0 and $100 \%$. While such heterogeneity of error can be reduced by angular transformation of cover data, significant interactions between observer and cover class $(\mathrm{P}<$ 0.01, see also Sykes et al. 1983), imply considerable difficulty in adjusting for errors across a range of covers if estimates are made by more than 1 observer.

The observer had a significant effect on visual estimates of cover in classified images, with average differences between 'percentage black' and 'estimated percentage black' ranging from 4 to $14 \%$ and estimates of 'percentage black' in individual test images out by as much as $30 \%$ (Table 1). Averaged across all observers, errors here were low $(7 \%)$ when compared with the 10 to $20 \%$ accuracy expected in field studies (Sykes et al. 1983, Kennedy and Addison 1987), reflecting the simplified task of estimating cover in 2-dimensional, duo-tone images. The arrangement of images did not significantly affect accuracy of visual estimates, but there were significant interactive effects between observer and image arrangement $(\mathrm{P}<$ $0.05)$ and between cover class and image arrangement $(\mathrm{P}<0.05)$; further evidence that errors associated with this method are unpredictable. For point sampling, the effect of point number on accuracy was highly significant $(\mathrm{P}<0.001)$. Differences between 'percentage black' and 'estimated percentage black', across all observations, were significantly greater using $10 \mathrm{com}$ pared to 20 points (10 vs $8 \%$ ), 20 compared to 50 points ( 8 vs $4 \%$ ), 50 compared to 100 points ( 4 vs $3 \%$ ), and $100 \mathrm{com}$ pared to 1000 points (3 vs 1\%, Table 1). Using this highly simplified evaluation of point sampling, 100 or more points per 1 $\mathrm{m}^{2}$ quadrat would be required to estimate total projective cover to within less than $5 \%$ across a range of cover classes. We would expect the required number to increase to at least 200 points in the field given additional sources of error due to inconsistencies associated with observer fatigue and observer perspective (that is, observation of points from oblique angles rather than directly above). This level of sampling could equate to as much as 4 field hours per quadrat (Stampfli 1991) and might be compared to the capacity to take 36 photographs within 2.5 hours using the photographic method described here.

The variable error of both the visual estimation and point sampling methods in simplified laboratory tasks, supported our preliminary conclusion that neither technique could provide measures of 'true' grass cover against which the photographic method could be assessed. Orthophotos, 
produced from stereoscopic pairs of subplot images, could provide a more accurate benchmark and will be compared with single images in future research. However, data presented here would indicate that the photographic method is sufficiently accurate and precise to measure treatment effects over time (Fig. 3), and to elucidate relationships between growth parameters across a range of conditions (Figs 4 and $5)$. Furthermore, the described photographic method captured and analysed images with ease and speed. Thus, a large number of small plots could potentially be measured either as contiguous plots in intensive studies or as single plots in nested designs over large areas (Stohlgren 1995, Stohlgren et al. 1998). Since the images were easily archived, data could be used in retrospective studies that examined new questions or that utilised improvements in interpretative tools such as image analysis procedures (Pace and Cole 1989). Finally, the use of objective color analysis to discriminate between plant and soil clearly suits the red soils and discontinuous litter of these sites and other sites within arid and semi-arid zones. Further evaluation of the method would be required to assess its potential in other herbaceous communities that are more diverse and structurally complex or that occur on different colored soils. Where distinguishing plant from soil is a problem, we suggest the trial of discrimination parameters using primary color values or intensity measures (Pan et al. 1998) or the use of wavelengths beyond the visible range such as infra-red.

\section{Literature Cited}

Austin, M. P. 1981. Permanent quadrats: an interface for theory and practice. Vegetatio 46:1-10.

Buttler, A. 1992. Permanent plot research in wet meadows and cutting experiment. Vegetatio 103:113-124.

Cooper, W. S. 1924. An apparatus for photographic recording of quadrats. J. Ecol. 12:317-321.

Friedel, M. H. and K. Shaw. 1987. Evaluation of methods for monitoring sparse patterned vegetation in arid rangelands. I. Herbage. J. Environ. Manage. 25:297-308.

Green, R. H. 1993. Application of repeated measures designs in environmental impact and monitoring studies. Australian J. Ecol. 18:81-98.

Kennedy, K. A. and P. A. Addison. 1987. Some considerations for the use of visual estimates of plant cover in biomonitoring. J. Ecol. 75:151-157.

Moore, R. M. 1970. Australian grasslands, $p$. 87-100. In: R. M. Moore (ed.), Australian grasslands. Australian Nat. Univ. Press, Canberra, A.C.T.

Owens, M. K., H. G. Gardiner, and B. E. Norton. 1985. A photographic technique for repeated mapping of rangeland plant populations in permanent plots. J. Range Manage. 38:231-232

Pace, M. L. and J. J. Cole. 1989. What questions, systems, or phenomena warrant longterm ecological study? p. 183-185. In: G. E. Likens (ed.), Long-term studies in ecology: Approaches and alternatives. SpringerVerlag, New York, N.Y.

Pan, W. L., R. P. Bolton, E. J. Lundquist, and L. K. Hiller. 1998. Portable rhizotron and color scanner system for monitoring root development. Plant Soil 200:107-112.
Pickup, G., G. N. Bastin, and V. H. Chewings. 1994. Remote-sensing-based condition assessment for nonequilibrium rangelands under large-scale commercial grazing. Ecol. Applications 4:497-517.

Roshier, D., S. Lee, and F. Boreland. 1997. A digital technique for recording of plant population data in permanent plots. J. Range Manage. 50:106-109.

Rowell, J. G. and D. E. Walters. 1976. Analysing data with repeated observations on each experimental unit. J. Agr. Sci. 87:423-432.

Stampfli, A. 1991. Accurate determination of vegetational change in meadows by successive point quadrat analysis. Vegetatio 96:185-194.

Stampfli, A. 1992. Year-to-year changes in unfertilized meadows of great species richness detected by point quadrat analysis. Vegetatio 103:125-132.

Stohlgren, T. J. 1995. Planning long-term vegetation studies at landscape scales, p. 209-241. In: T. M. Powell and J. H. Steele (eds.), Ecological time series. Chapman and Hall, New York, N.Y.

Stohlgren, T. J., K. A. Bull, and Y. Otsuki. 1998. Comparison of rangeland vegetation sampling techniques in the Central Grasslands. J. Range Manage. 48:187-190.

Sykes, J. M., A. D. Horrill, and M. D. Mountford. 1983. Use of visual cover assessments as quantitative estimators of some British woodland taxa. J. Ecol. 71:437-450.

Tongway, D. and Hindley N. 1995. Manual for soil condition assessment of tropical grasslands. CSIRO Australia, Canberra, A.C.T.

Underwood, A. J. 1997. Experiments in ecology: Their logical design and interpretation using analysis of variance. Cambridge Univ. Press, Cambridge, United Kingdom.

Walker, B. H. 1970. An evaluation of eight methods of botanical analysis on grasslands in Rhodesia. J. Appl. Ecol. 7:403-416. 